\title{
Profile of epilepsy patients in Pediatric Ward at Dr. Soetomo General Academic Hospital, Surabaya, Indonesia in the period of January-December 2017
}

\author{
Dewi Sekarsari ${ }^{1}$, Viskasari P. Kalanjati ${ }^{1 *} \mathbb{D}$, Abdulloh Machin ${ }^{2}$, Prastiya I. Gunawan ${ }^{3} \mathbb{C}$ \\ ${ }^{1}$ Department of Anatomy, Histology and Pharmacology, Faculty of Medicine, Universitas Airlangga, \\ Surabaya, Indonesia, ${ }^{2}$ Department of Pediatrics, Dr. Soetomo General Academic Hospital, Surabaya, \\ Indonesia, ${ }^{3}$ Department of Neurology, Dr. Soetomo General Academic Hospital, Surabaya, Indonesia
}

\begin{tabular}{l}
\hline Article Info \\
\hline Article history: \\
Received Feb 15, 2020 \\
Revised Mar 25 2020 \\
Accepted Apr 2, 2020 \\
Published Jul 1, 2020 \\
\hline
\end{tabular}

Keywords:

Epilepsy

Children

Febrile seizure

\begin{abstract}
Background: Various risk factors of epilepsy in children had been reported although differences were found amongst regions. Objective: To identify the profile of epilepsy patients and previous febrile seizure history in children aged 0-17 years at Pediatric Ward, Dr. Soetomo General Academic Hospital, Surabaya, Indonesia, in 2017. Materials and Methods: This was a cross-sectional retrospective study, using secondary data from medical records of epilepsy patients with febrile seizure history in children aged 0-17 years old at Pediatric Ward, Dr. Soetomo General Academic Hospital, Surabaya, Indonesia, in the period of January-December 2017. Data analysis was done using t-test and Chi- Square test (Microsoft Excel 2007 and SPSS 22). The level of significance was p $<0.05$. Results: Seventy-four male and 38 female patients were included. Febrile seizure history was observed in 42 patients and there was no significant difference between febrile seizure history and prevalence of epilepsy. The general type of seizure was found in 79 patients; mostly from Surabaya, Indonesia and the parents' occupation was private employee. The most observed type of seizure was general type. Conclusion: In this study, epilepsy was predominantly found in males than females; and a significant number of the patients were without febrile seizure history. General type of seizure was the most common type amongst others. These patients were mostly from Surabaya, Indonesia, whose parents' occupation was private employees.
\end{abstract}

\section{Corresponding Author:}

\section{Viskasari P. Kalanjati}

Department of Anatomy, Histology and Pharmacology, Faculty of Medicine, Universitas Airlangga Jl. Mayjen. Prof. Moestopo no. 47, Surabaya 60131, East Java, Indonesia

viskasari-p-k@fk.unair.ac.id.

\section{BACKGROUND}

Epilepsy is one of the most common neurological disorder which can lead to severe neurobehavioral damaged in children affecting their growth and developmental process. The incidence of epilepsy is still relatively high in underdeveloped countries (Gencpinar, 2017). The incidence reaches 114 per 100,000 populations per year. Compared to developed countries, the incidence of epilepsy in underdeveloped countries per year is between 24 and 53 cases per 100,000 populations (Sander and Holthausen, 2017). These risk factors are divided into internal and external risk factors. Internal risk 
factors include a family history of illness which is then associated with genetic factors, the presence/absence of febrile seizure history or epilepsy. External risk factors include demographic factors, the level of family welfare, and the parents' education level of understanding a seizure in children (Besli et al., 2010)

Febrile seizure is one of the most common neurological disorders in children. More than $90 \%$ of cases of febrile seizure occur in children under the age of 5 years. Febrile seizure are seizure caused by an increase in body temperature of more than $38^{\circ} \mathrm{C}$ without any central nervous system infections or acute electrolyte disorders in children aged 0-5 years (Chung, 2014). Generally, febrile seizure is not lifethreatening if their duration is less than 15 minutes and it occurs no more than once in 24 hours (Patterson et al., 2013). In Japan, children affected febrile seizure is more frequent compared to children in United States and Western Europe is 9,3\% and 5\% respectively. Male children are reported to have higher incidence than females. Although some studies have shown no significant gender difference (Chung, 2014).

Febrile seizures are generally benign, but tend to recur and increase the risk of development of epilepsy in children (Gencpinar, 2017). In United States, about 20-40\% of children with febrile seizure developed epilepsy by age 7 years (Camfield, 2015). This is caused by the presence of more than one risk factors, especially a preexisting neurodevelopmental disease, a positive family history of epilepsy, and two or more complex features of seizure. Thus, the risk of epilepsy after single febrile seizure can be slightly elevated if they are recurrent (Khair, 2015). In Saudi, a study found that three complex febrile seizure more than 15 minutes is the only factor which associated with later epilepsy (Almojali,2017).

In the current study, we would like to determine the profile of epilepsy patients and febrile seizure history in children aged 0-17 years at Pediatric Ward, Dr. Soetomo General Academic Hospital. This study would provide an overview of some of the risk factors useful for the prevention and treatment of epilepsy in children.

\section{OBJECTIVE}

This study was conducted to identify the profile of epilepsy patients and previous febrile seizure history in children aged 0-17 years at Pediatric Ward, Dr. Soetomo General Academic Hospital, Surabaya, Indonesia, in 2017.

\section{MATERIALS AND METHODS}

This research was an observational analytic study using a cross-sectional design on the data of medical records of epilepsy patients with febrile seizure history in children aged 0-17 years at Pediatric Ward, Dr. Soetomo General Academic Hospital, Surabaya, Indonesia in January- December 2017. There were 124 pediatric patients diagnosed with epilepsy in that period. The number of patients who met the inclusion criteria was 112 patients. Patients aged above 17 years or having incomplete data were excluded. We analysed the febrile seizure history, sex and type of seizure. Patient sociodemography was represented by the patient's home address and parents' occupation. Data processing was performed with Microsoft Excel 2007 and SPSS 22 using the Chi-square and also t-test with the significance level of $\mathrm{p}<0.05$.

\section{RESULTS}

During this period, 124 epilepsy patients were found. From the total number of epilepsy patients, there were 112 patients who met the inclusion criteria, $74(66 \%)$ of whom were male and $38(34 \%)$ were female. Febrile seizure history was found in 42 patients (38\%) and 70 other patients had no febrile seizure history (62\%). There were no significant results between febrile seizure history and epilepsy (p>0.05). Based on the types of seizure in epilepsy, 79 patients were found with general seizure $(71 \%)$, 30 patients with focal seizure type (27\%) and the other type was infantile spasm in 3 patients $(2 \%)$ (Table 1).

Most of the patients came from Surabaya, Indonesia, which was 69 patients $(62 \%)$; from other cities were 17 patients including from Sidoarjo (15\%), 8 patients from Madura (7\%), and 16\% came from other cities. The parents' occupation is composing i.e. 24 private employees $(21 \%), 17$ entrepreneurs 
(15\%) and 64\% are other occupations such as housewives, door-to-door salesmen, security guards, farmers and others (Table 2).

Table 1. General characteristics of epilepsy patients in children.

\begin{tabular}{|c|c|c|c|}
\hline Characteristics & $\begin{array}{l}\text { Amount } \\
(\mathrm{n}=112)\end{array}$ & Percentage & $p$ \\
\hline Sex & & & 0.248 \\
\hline 1. Male & 74 & $66 \%$ & \\
\hline 2. Female & 38 & $34 \%$ & \\
\hline Febrile Seizure History & & & 0.438 \\
\hline 1. Available & 42 & $38 \%$ & \\
\hline 2. None & 70 & $62 \%$ & \\
\hline Types of Seizure & & & 089 \\
\hline 1. General Seizure & 79 & $71 \%$ & \\
\hline 2. Focal Seizure & 30 & $27 \%$ & \\
\hline 3. Others: Infantile Spasm & 3 & $2 \%$ & \\
\hline
\end{tabular}

Table 2. Demographic data of epilepsy patients in children.

\begin{tabular}{lcc}
\hline \multicolumn{1}{c}{ Demographic data } & $\begin{array}{c}\text { Amount } \\
(\mathrm{n}=112)\end{array}$ & Percentage \\
\hline Address & & \\
$\quad$ Surabaya & 69 & $62 \%$ \\
$\quad$ Sidoarjo & 17 & $15 \%$ \\
$\quad$ Madura & 8 & $16 \%$ \\
Parents' Occupation & & \\
$\quad$ Private employees & 24 & $21 \%$ \\
$\quad$ Entrepreneurs & 17 & $15 \%$ \\
$\quad$ Others (housewives. door-to- door & 71 & 64 \\
$\quad$ salesmen, security guards, farmers) & & \\
\hline
\end{tabular}

\section{DISCUSSION}

In this study, male patients were approximately twice the number of female patients. Similar results were also obtained in previous studies conducted by Suwarba (2011); more male than female patients were found among pediatric epilepsy patients at Sanglah Hospital, Denpasar, Bali (Suwarba, 2011). In Istanbul, however, a study identified that the incidence of epilepsy between males and females is 29 and 27, respectively (Besli et al., 2010). However, it was reported that the incidence of epilepsy in children had no significant relationship with sex, but was very closely related to the age of the child when the first seizure occurred (Besli et al., 2010). Moreover, a retrospective study in Jeju, Korea found that a febrile seizure will likely develop to an epilepsy which shows significant factors: (1) Late onset of febrile seizure at age $>3$ years, (2) Complex features in the first febrile seizure, (3) family history of epilepsy, (4) Abnormal findings on EEG, and (5) febrile seizure developed at a body temperature of $<39^{\circ} \mathrm{C}$ (Hwang, 2015).

We also found, the epilepsy patients who had febrile seizure history were approximately half the number of patients without febrile seizure history; there was no significant correlation between epilepsy to the febrile seizure history in this study. Similar results were also obtained in previous studies at Sanglah Hospital, Denpasar where the percentage of epilepsy patients without a febrile seizure history was higher than epilepsy patients with febrile seizure history (10.1\% vs. 89.9\%) (Suwarba, 2011). A study conducted by Pavlidou (2013), analyzed that epilepsy after febrile seizure occurred in $27(5,4 \%)$ of 501 children. Whereas other 460 children $(91,8 \%)$ had no previous febrile seizure. A occurrence of epilepsy after the first febrile seizure ranged from 6 to 42 months. Another population-based cohorts study determined that $15 \%$ 
children with epilepsy had a previous febrile seizure and lead to the conclusion that febrile seizures rarely lead to epilepsy but epilepsy is fairly frequently preceded by febrile seizure (Camfield, 2015).

Other than febrile seizure, a cohort study in Brazil showed that high risk of early epilepsy is associated with zika-related microcephaly. Although, febrile seizure is only found in $11 \%$ children, and the main type of first seizure was infantile spasm $(56 \%)$ which developed into epilepsy (Carvalho, 2020). On the contrary, in our study we found that only $3(2 \%)$ of 112 children who had history of infantile spasm which developed into epilepsy.

Previous study analyzed that epilepsy is differed between the number of seizures within the first 2 years after febrile seizure onset $(\mathrm{P}<0.001)$, developmental delay $(\mathrm{P}<0.001)$, history of preterm birth $(\mathrm{P}=0.001)$, multiple seizures per febrile episode $(\mathrm{P}=0.005)$, and abnormal EEG findings $(\mathrm{P}=0.008)$. Meanwhile, other factors such as gender, distribution, seizure duration, peak temperature, focality of seizure and family history of epilepsy were not significant factors for epilepsy diagnostic in children (Lee, 2016).

Most patients of the current study were diagnosed of having general type of seizure. This is in line with research conducted by Suwarba (2011) where the percentage of general seizure of epilepsy in the pediatric patients reached approximately 80\% (Suwarba, 2011). One of the commonest comorbid is the cerebral palsy (CP). This may underlie high incidence of general type of seizures in children with epilepsy (Rahmat \& Mangunatmadja, 2016).

In this study, more patients came from Surabaya than from outside of Surabaya. In addition, the parents' occupations were mostly private employees although this percentage of data was dominated by other types of work that were not clearly detailed. Although a study conducted by Kanemura (2012) found that sociodemographics factor were not correlated with epilepsy incidence, education of the parents was highly recommended for a self-diagnosis of recurrent febrile seizure, which is very important to know because it is one of the predisposing factors for epilepsy later in life (Patterson et al., 2013). Parents' understanding on the difference between epilepsy and recurrent febrile seizure can be affected by many factors due to signs and symptoms that are often difficult to be distinguished. Thus, epilepsy management is often belated, and results in relatively high mortality and morbidity in children (Patterson et al., 2013).

\section{CONCLUSION}

Factors such as sex, previous febrile seizure history, type of seizure and sociodemographics do not have significant relationship with later development of epilepsy. Although febrile seizure in children is self-limiting, children with predisposing factors of epilepsy should be observed carefully to reduce mortality and morbidity rate in children.

\section{REFERENCES}

Almojali, A.I., et al., 2017. Prognostic factors for epilepsy following first febrile seizure in Saudi children. Annals of Saudi Medicine, 37(6): 449-54.

Besli, G.E, et al., 2010. Status epilepticus in children: Causes, clinical features and short-term outcome: Status epilepticus in children. Pediatrics International, 52(5): 749-53.

Camfield, P., Camfield, C., 2015. Incidence, prevalence and aetiology of seizures and epilepsy in children. Epileptic Disorders, 17(2): 117-23.

Camfield, P., Camfield, C., 2015. Febrile seizures and genetic epilepsy with febrile seizures plus (GEFS+). Epileptic Disorders, 17(2): 124-33.

Carvalho, M.D.C.G., et al. 2020. Early epilepsy in children with zika- related microcephaly in a cohort in Recife, Brazil: Characteristics, electroencephalographic findings, and treatment response. Epilepsia, 61(3): 509-18.

Chung, S., 2014. Febrile seizures. Korean Journal of Pediatrics, 57(9): 384. 
Gencpinar, P, et al., 2017. The risk of subsequent epilepsy in children with febrile seizure after 5 years of age. Seizure, 53: 62-5.

Hwang, G., et al. 2015, Predictors of unprovoked seizure after febrile seizure: short-term outcomes. Brain and Development, 37(3): 315-21.

Kanemura, H., et al. Duration of recognized fever in febrile seizure predicts later development of epilepsy: Duration of recognized fever in FS. Pediatrics International, 54(4): 520-3.

Khair, A.M., Elmagrabi, D., 2015. Febrile seizures and febrile seizure syndromes: An updated overview of old and current knowledge. Neurology Research International, 2015: 1-7.

Lee, S.H., et al. 2016. Epilepsy in children with a history of febrile seizures. Korean Journal of Pediatrics, 59(2): 74.

Patterson, J.L., et al., 2013. Febrile seizures. Pediatric Annals, 42(12)

Pavlidou, E., Panteliadis, C., 2013. Prognostic factors for subsequent epilepsy in children with febrile seizures. Epilepsia, 54(12): 2101-7.

Rahmat, D., et al. 2010. Prevalence and risk factors for epilepsy in children with spastic cerebral palsy. Paediatrica Indonesiana, 50(1): 11-7.

Sander, G., Holthausen, H., 2017. Epilepsy after cerebral infection: review of the literature and the potential for surgery. Epileptic Disorders, 19(2): 117-136.

Suwarba, I. 2016. Insidens dan karakteristik klinis epilepsi pada anak [Incidence and clinical characteristics of epilepsy in children]. Sari Pediatri, 13(2): 123. 